\title{
Residual characteristics of pesticide in banana from international pesticide residue monitoring data
}

\author{
Seo-Hong Kim ${ }^{1}$ (I) $\cdot$ Jeong-Ah Kim ${ }^{2}$ (1) $\cdot$ Moo-Hyeog Im $^{2}$ (1) \\ 각국의 잔류농약 모니터링 자료를 활용한 바나나 중 농약 잔류 실태 조사
}

김서홍 ${ }^{1} \cdot$ 김정아 ${ }^{2} \cdot$ 임무혁 $^{2}$

Received: 11 October 2019 / Accepted: 26 December 2019 / Published Online: 31 March 2020

(C) The Korean Society for Applied Biological Chemistry 2020

\begin{abstract}
This study was designed to use the safety management data for residual pesticides in imported banana based on the investigation of pesticide residue detection of agricultural products with different origins in the Republic of Korea. From the USA, EU, UK, Japan and Korea from 2007 to 2018, the results of banana residue pesticides were summarized into detected pesticides, number of inspections, number of pesticide detection cases, and the amount of detected pesticide residue. A total of 109 pesticides were detected for the pesticide residue and pesticide detection rate was $4.58 \%$ in 206,894 cases. The detection rate was ranged within $10.62-24.62 \%$ for chlorpyrifos, imazalil, methyl-bromide, azoxystrobin, carbendazim, pretilachlor and thiabendazole. Among them, chlorpyrifos was detected most often followed by imazalil, azoxystrobin, thiabendazole, bifenthrin and carbendazim. According to the results of monitoring data for bananas in EU, Japan, USA, UK and Korea, the kinds of detected pesticides were 85, 57, 23, 18 and 8, respectively. Azoxystrobin, bifenthrin and chloropyrifos were found in monitoring data of all countries. Fourteen and twelve pesticides were detected in bananas from Costa Rica and
\end{abstract}

Moo-Hyeog $\operatorname{Im}(\bowtie)$

E-mail:imh0119@daegu.ac.kr

${ }^{1}$ Department of Environmental and Biological Chemistry, Chungbuk National University, Chungbuk, Republic of Korea

${ }^{2}$ Department of Food Engineering, Daegu University, Gyeongbuk, Republic of Korea

This is an Open Access article distributed under the terms of the Creative Commons Attribution Non-Commercial License (http://creativecommons. org/licenses/by-nc/3.0/) which permits unrestricted non-commercial use, distribution, and reproduction in any medium, provided the original work is properly cited.
Ecuador, respectively. Imazalil and thiabendazole were detected in 16 and 11 origins, respectively. Myclobutanil and iprodione were detected in four and two countries, respectively. In bananas from Costa Rica, azoxystrobin and bifenthrin were detected 11.8 and $9.8 \%$, respectively, and the detection rate of azoxystrobin was $19 \%$ in bananas from Colombia. Chlorpyrifos was detected 22.7, 13.3 and $10.8 \%$ in bananas from Belize, Colombia and Costa Rica respectively. Myclobutanil was detected in bananas from Colombia and Costa Rica with the rate of 17.9 and $10.4 \%$, respectively.

Keywords Banana - Imported food $\cdot$ Monitoring $\cdot$ Pesticide residues

\section{서 론}

바나나는 파초과에 속하는 상록 여러해살이 풀로 처음 열매를 맺기까지는 9개월 정도가 소요되며, 바나나 열매는 4-6개월마다 수확하여 1년에 2-3회 수확하기 때문에 수확량이 많은 편이다 [1]. 뿐만 아니라, 영양가가 높아 20세기 초 미국의학협회 (American Medical Association)에서 승인한 최초의 수퍼푸드 타이틀을 받은 과일로 세계 5대 식량 작물인 옥수수, 콩, 밀, 보리 및 감자를 대체할 수 있어서 그 가치의 중요성이 증가하 고 있다[2]. 주로 인도, 중국, 필리핀 등 아시아에서 $50 \%$ 이상, 아프리카에서 $18 \%$, 브라질, 에콰도르, 콜롬비아 등 남미에서 $16 \%$, 그 외 중미 $9 \%$ 정도 생산되어 세계 각국으로 유통되고 있다[3].

우리나라에서 바나나의 수입량은 국내 수입 과실류 중에서 가장 많은 비중을 차지하고 있으며 꾸준히 일정량을 유지하며 증가하고 있다[4]. 바나나의 1 일 국민 평균 섭취량도 국민의 상 
시 섭취 식품인 깻잎, 고사리 및 취나물 보다 많이 섭취하고 있 는 편이다[5]. 우리나라는 주로 필리핀, 과테말라, 에콰도르 및 페루에서 생산된 바나나를 수입하고 있다[6]. 수입 바나나는 2014년 iprodione 및 prochloraz 각각 21 및 1건, 2015년 iprodione 및 prochloraz 각각 15 및 4건, 2016년 iprodione 5건, 2017년 iprodione, pyraclostrobin 및 fipronil 각각 2, 1 및 1건으로 통 관 검사에서 잔류농약 부적합을 발생시켜 잔류농약 부적합으로 보고되었다[7-10].

바나나에 대한 잔류농약 모니터링은 우리나라를 비롯하여 미 국, 일본, 영국 및 $\mathrm{EU}$ 각국에서 수입 통관 절차 및 유통 식품 모니터링으로 검사하는 경우가 대부분이다[11]. 바나나는 열대 및 아열대 기후에서 생산되므로 우리나라 등 대부분 국가가 수 입에 의존하고 있고, 생장 기간 중은 물론이고 선박을 이용한 긴 운송기간동안 숙도조절 및 해충방제를 위하여 수확 후에도 농약을 처리하고 있다. 작물의 생장기간동안 살포된 농약은 태 양광과 같은 외부 환경 및 작물의 생장과 함께 희석 효과를 보 여 초기 잔류량이 빠르게 분해 및 소실되지만, 저장기간 중 살 포되는 농약의 잔류에 대하여 관리가 철저히 이루어져야 한다 $[12,13]$. 잔류농약에 대한 대부분 연구논문은 분석방법 등에 대 한 내용으로 정부차원의 규제 모니터링 결과 이외에 연구 차원 의 바나나 잔류농약 모니터링 연구는 드물다[14,15]. 바나나에 대한 잔류농약 모니터링 연구 보고를 살펴보면, 이탈리아로 수 입된 에콰도르, 파나마 및 코스타리카산 바나나 50건에 대하여 benzimidazole계 살균제인 benomyl, carbendazim, thiabendazole 및 thiophanate-methyl 모니터링 연구와 스페인 카나리 제도 현 지 시장에서 수거한 바나나 57건을 살충제인 ethoprophos, dimethoate, diazinon, malaoxon, chlorpyrifos-methyl, fenitrothion, malathion, chlorpyrifos, fenamiphos, buprofezin 및 phosmet 11종의 모니터링에 대한 연구에 불과하다[16,17].

따라서 본 연구에서는 우리나라뿐만 아니라 미국, $\mathrm{EU}$, 일본 및 영국의 잔류농약 모니터링 자료를 이용하여 바나나 중 검출 농약을 조사하고 이 검출 농약에 대한 검출률 및 잔류량을 수 집하고 정리하여 검출 경향을 비교 및 분석하여 우리나라의 바 나나에 대한 잔류농약 안전관리를 위한 기초자료로 활용할 수 있도록 하였다.

\section{바나나의 잔류농약 모니터링 자료 수집}

바나나의 잔류농약 모니터링 자료는 미국 Food and Drug Administration (FDA), 일본 후생노동성, 유럽연합(European Union, EU) European Food Safety Authority (EFSA) 및 Rapid Alert System for Food and Feed (RASFF), 영국 (United Kingdom, UK) Health and Safety Executive (HSE) 및 대한민국 식품의약품안전처(Ministry of Food and Drug Safety, MFDS)의 잔류농약 모니터링 보고서 중 바나나 모니터 링 결과가 있는 연도의 자료와 각국 정부에서 발표한 잔류농약 부적합 자료를 수집하였다.

미국은 FDA 홈페이지에 모니터링 원자료를 제공해 주고 있 으며 이들 중 검출 이력이 있는 자료만 사용하였다. 2010-2016 년 신선 바나나를 비롯한 바나나 스낵 및 음료와 같은 가공식 품 및 플랜테인의 잔류농약 자료가 모두 바나나로 포함되어 본 연구를 위하여 활용되었다[18].

일본은 후생노동성 홈페이지에서 2007-2015년 모니터링 자료
와 2013 및 2016-2018년 수입식품 중 잔류농약 부적합 발표 자료를 사용하였다[19,20]. 일본의 모니터링 자료 중 수입식품 은 원산지가 표시되지 않고 수입으로만 표시되어 있다. 수입식 품 부적합 모니터링 발표 사이트를 참고하여 페루 및 필리핀에 서 수입된 바나나가 부적합 되었음을 추정 할 수 있었으나 원 산지를 수입(일본)으로 처리 하였다.

$\mathrm{EU}$ 의 자료는 $\mathrm{EFSA}$ 에서 발표한 2009-2015년 식품 중 잔류 농약에 대한 보고서 및 RASFF 홈페이지에서 2014, 2016 및 2017년 잔류농약 부적합 자료를 사용하였다[21,22]. EFSA는 모 든 보고 국가의 주요 소비 식품 및 자주 발생하는 잔류농약에 대하여 통계적으로 나타나는 결과를 제공하는 것을 목표로 하 여 EU 모니터링 프로그램(EU-coordinated programme, EUCP) 에 따라 1 년 단위 3 년 주기로 바나나를 포함한 일반적 주요 소 비 식품 30 여 개를 정기적으로 모니터링하고 있으며 이를 보충 하기 위하여 국가별 프로그램(National control programmes for pesticide residues, NCP)을 통한 모니터링도 이루어지고 있다. $\mathrm{EU}$ 의 자료는 시료 수, 검사 농약 수 및 검출 건수를 알 수 있 었으나 일부는 검출 빈도가 높은 4-5개 농약의 검출률만 제공 되어 검출 건수로 재전환 하였고, 각 시료의 검출 건수가 분명 하지 않은 경우는 1건으로 처리하였다.

영국의 자료는 HSE 홈페이지에서 2012 및 2015-2018년의 생산단계, 유통단계 및 학교급식 잔류농약 모니터링 조사 자료 를 사용하였다[23-25]. 영국의 식품 중 잔류농약 모니터링 계획 및 결과는 2011년 이후부터 잔류농약전문가위원회(Expert Committee on Pesticide Residues in Food, PRiF)에 의해 감 독 되고 분기별로 보고서를 발간한다. 바나나는 껍질 및 과육 을 포함한 전체 과일을 대상으로 하며 롤링프로그램(Rolling Programme)에 의해 3년 주기로 조사되고 있다.

우리나라 MFDS의 자료는 식품의약품안전평가원(National Institute of Food and Drug Safety Evaluation, NIFDS)의 잔 류농약 모니터링 관련 연구보고서에서 바나나 중 잔류농약 검 출이력이 있는 2012, 2013, 2015 및 2016년 자료를 이용하였 다[26]. 원산지는 시료 별로 분명하게 구분을 할 수 없어서 수 입(한국)으로 표시하였다. 바나나는 국내에서 재배를 시도하고 있지만 현재 전량 수입에 의존하고 있으며 국내 유통단계에서 원산지 표기를 하지 않고 모니터링을 실시한 결과이기 때문이다.

각 국가별로 발췌된 자료는 내용을 발표연도, 검사국, 발표기 관, 원산지, 검출 농약, 검사 건수, 검출 건수 및 잔류량으로 정 리하고 통합하여 사용하였다. 바나나 생산국을 파악할 수 있는 경우에는 원산지 기준으로도 정리하여 바나나 생산지별 잔류 실 태를 파악할 수 있도록 하였다. 검출 농약의 명칭은 국내 시험 법에 따라 검출되는 농약 성분으로 정리하여 농약 성분별 잔류 실태를 파악하도록 하였고, benomyl 및 thiophanate-methyl은 carbendazim으로, triadimefon은 triadimenol로, thiodicarb는 methomyl로, maneb, mancozeb, metiram, propineb, thiram 및 ziram은 dithiocarbamates로, omethoate는 dimethoate로 통합하 였다. 검사 건수는 분석된 시료 수를 알 수 있는 경우에 시료 수로 명시하였고, 검출 건수는 정량한계(Limit of Quantification, $\mathrm{LOQ}$ ) 이상 검출된 결과를 자료로 사용하였다. 검사 건수 및 검 출 건수가 명시되지 않고 잔류량만 있으면 검사 건수 및 검출 건수를 같도록 처리하였다. 잔류량은 보고된 자료를 그대로 인 용하였으며, 평균과 최대 및 최소와 최대 잔류량을 같이 알 수 
있는 경우에는 최대 잔류량을 선택하였다. 검사 건수 및 검출 건수는 알 수 있으나 잔류량이 명시되지 않은 경우는 잔류량을 공란으로 처리하였다.

\section{바나나의 잔류농약 모니터링 결과}

총 109 종 농약이 미국, $\mathrm{EU}$, 영국, 일본 및 우리나라에서 실시 한 바나나의 잔류농약 모니터링 자료에서 검출되었다. Table 1 은 검출 농약 목록으로 총 검사 건수, 검출 건수(검출률) 및 최 고 잔류량을 표시하고 한국 및 Codex의 바나나에 대한 잔류허 용기준(Maximum Residue Levels, MRLs)과 비교할 수 있도록 나타내었다[27,28]. 전체적으로 잔류농약은 109 종 농약에 대하 여 206,894 건을 검사하여 9,483 건에서 검출되어 $4.58 \%$ 의 검출 률을 나타내었다. 농약 검출 건수는 chlorpyrifos 2,344건, imazalil 1,848건, azoxystrobin 1,202건, thiabendazole 977건, bifenthrin 640건 및 carbendazim 579건의 순으로 조사되었다.

검출된 109 종 농약 중에서 chlorpyrifos가 9,520 건 검사에서 2,344 건의 농약이 검출되어서 검출률이 $24.62 \%$ 로 가장 높은 결 과를 보였다. Chlorpyrifos는 접촉, 식독 및 호흡을 통한 넓은 작용점을 가지고 광범위한 해충에 효과가 있는 유기인계 살충 제이며 $\mathrm{K}_{\mathrm{ow}}$ 값이 4.7 로 잔류될 확률이 다른 농약에 비해 높은 편이다[29].

Imazalil은 8,309 건 검사 결과, 1,848 건이 검출되어 $22.24 \%$ 의 검출률을 보였으며, 이 농약은 광범위하게 사용되고 있는 이행 성 키랄 살균제로 거울상 이성질체의 차이를 구별하지 않는 라 세미 혼합물이다[30].

Methyl-bromide, azoxystrobin, carbendazim, pretilachlor 및 thiabendazole이 각각 $22.03,13.79,13.75,12.37$ 및 $10.62 \%$ 의 검출률을 나타내었다. 광범위한 곰팡이 방제에 효과가 있는 침 투성 살균제 carbendazim은 4,212건 검사하여 579건 검출되어 $13.75 \%$ 의 상대적으로 높은 검출률을 보였으나, imidacloprid, pyrimethanil, cyhalothrin 및 difenoconazole은 5,146-6,780건의 많은 검사 건수에도 불구하고 각각 $0.55,0.56,0.82$ 및 $0.19 \%$ 의 검출률로 상대적으로 낮은 검출률을 나타내었다.

2012년 EU EFSA 보고서에 의하면 acrinathrin이 포르투갈산 바나나에서 $3.3 \mathrm{mg} / \mathrm{kg}$ 의 높은 잔류량을 나타내었는데, 당시 $\mathrm{EU}$ 의 $\mathrm{MRL}$ 은 $0.5 \mathrm{mg} / \mathrm{kg}$ 이었다[31]. 현재는 우리나라 및 $\mathrm{EU}$ 의 acrinathrin에 대한 바나나의 MRL은 각각 0.01 및 $0.02 \mathrm{mg} / \mathrm{kg}$ 이다[27,32].

검출 농약들의 최고 잔류량이 우리나라에서 농약허용물질목 록관리제도(Positive List System, PLS)가 시행된 현재 검출되었 다고 가정하였을 때, 우리나라의 바나나에 대한 잔류허용기준이 있는 농약 중 기준 초과에 해당하는 농약은 acrinathrin, azoxystrobin, bifenthrin, bitertanol, buprofezin, carbendazim, clothianidin, endosulfan, imazalil, imidacloprid, iprodione, tebuconazole, thiabendazole, thiamethoxam 및 trifloxystrobin이 었다. 2-Phenylphenol, atrazine, biphenyl 및 cyfluthrin 등 기준 이 없는 농약 59 종은 $0.01 \mathrm{mg} / \mathrm{kg}$ 의 불검출 수준 관리를 적용 받게 될 것이다. 실제 우리나라의 모니터링 자료를 살펴보면 수 입 바나나는 기준이 없는 미등록 농약에 대한 검출률이 높았다 [26]. 바나나에 대한 기준 설정 농약 수는 PLS 실시로 42종에 서 83종으로 증가되었다[27,33]. 대한민국의 수입식품 중 농약 잔류허용기준(Import Tolerance, IT) 설정은 2019년 1월 1일부

Table 1 Trends of the detection of residual pesticide in bananas among global residual pesticide monitoring results from 2007 to 2018

\begin{tabular}{|c|c|c|c|c|c|c|}
\hline \multirow{2}{*}{ No. } & \multirow{2}{*}{ Detected Pesticide } & \multirow{2}{*}{$\begin{array}{c}\text { No. of Samples } \\
\text { Analyzed }\end{array}$} & \multirow{2}{*}{$\begin{array}{l}\text { No. of Samples Detected } \\
\text { (Detection Rate \%) }\end{array}$} & \multirow{2}{*}{$\begin{array}{c}\text { Residue } \\
\text { Concentration } \\
(\mathrm{Max}, \mathrm{mg} / \mathrm{kg})\end{array}$} & \multicolumn{2}{|c|}{$\operatorname{MRLs}^{\mathrm{d})}(\mathrm{mg} / \mathrm{kg})$} \\
\hline & & & & & Korea & Codex \\
\hline 1 & 2-Phenylphenol & 2,311 & $6(0.26)$ & 0.07 & & \\
\hline 2 & Acetamiprid & 2,469 & $6(0.24)$ & 0.04 & 0.4 & \\
\hline 3 & Acibenzolar-S-methyl & 229 & $1(0.44)$ & $0.07^{\mathrm{b})}$ & & 0.06 \\
\hline 4 & Acrinathrin & 2,315 & $74(3.2)$ & $3.3^{\mathrm{a})}$ & 0.01 & \\
\hline 5 & Atrazine & 327 & $1(0.31)$ & 0.04 & & \\
\hline 6 & Azinphos-methyl & 1 & $1(-)$ & 0.0177 & 1.0 & \\
\hline 7 & Azoxystrobin & 8,718 & $1,202(13.79)$ & $2.04^{\mathrm{c})}$ & 2.0 & 2 \\
\hline 8 & Bifenthrin & 8,073 & $640(7.93)$ & $0.2^{\mathrm{c})}$ & 0.1 & 0.1 \\
\hline 9 & Biphenyl & 36 & $2(5.56)$ & 0.01 & & \\
\hline 10 & Bitertanol & 3,743 & $72(1.92)$ & $1.2^{\mathrm{c})}$ & 0.5 & 0.5 \\
\hline 11 & Boscalid & 4,669 & $50(1.07)$ & 0.5 & 0.6 & 0.6 \\
\hline 12 & Bromophos-methyl & 110 & $1(0.91)$ & 0.01 & & \\
\hline 13 & Bromopropylate & 1,659 & $2(0.12)$ & 0.02 & 5.0 & \\
\hline 14 & Bupirimate & 1,324 & $2(0.15)$ & 0.02 & & \\
\hline 15 & Buprofezin & 5,100 & $185(3.63)$ & $0.97^{\mathrm{c})}$ & 0.2 & 0.3 \\
\hline 16 & Captan & 51 & $3(5.88)$ & 0.019 & & \\
\hline 17 & Carbaryl & 655 & $5(0.76)$ & 0.02 & & \\
\hline 18 & Carbendazim & 4,212 & $579(13.75)$ & $0.29^{\mathrm{c})}$ & 0.2 & 0.2 \\
\hline 19 & Chlorfenapyr & 3,838 & $131(3.41)$ & 0.08 & 0.1 & \\
\hline 20 & Chlorothalonil & 1,444 & $10(0.69)$ & 0.1 & 3.0 & 15 \\
\hline
\end{tabular}


Table 1 Continued

\begin{tabular}{|c|c|c|c|c|c|c|}
\hline \multirow{2}{*}{ No. } & \multirow{2}{*}{ Detected Pesticide } & \multirow{2}{*}{$\begin{array}{l}\text { No. of Samples } \\
\text { Analyzed }\end{array}$} & \multirow{2}{*}{$\begin{array}{l}\text { No. of Samples Detected } \\
\text { (Detection Rate \%) }\end{array}$} & \multirow{2}{*}{$\begin{array}{c}\text { Residue } \\
\text { Concentration } \\
\text { (Max, mg/kg) }\end{array}$} & \multicolumn{2}{|c|}{$\mathrm{MRLs}^{\mathrm{d})}(\mathrm{mg} / \mathrm{kg})$} \\
\hline & & & & & Korea & Codex \\
\hline 21 & Chlorpropham & 2 & $2(-)$ & 0.013 & 0.05 & \\
\hline 22 & Chlorpyrifos & 9,520 & $2,344(24.62)$ & 1.88 & 2.0 & 2 \\
\hline 23 & Chlorpyrifos-methyl & 2,631 & $7(0.27)$ & 0.08 & & \\
\hline 24 & Clofentezine & 1,110 & $2(0.18)$ & 0.03 & 1.0 & \\
\hline 25 & Clothianidin & 854 & $29(3.4)$ & $0.07^{\mathrm{c})}$ & 0.02 & 0.02 \\
\hline 26 & Cyfluthrin & 2 & $2(-)$ & 0.0142 & & \\
\hline 27 & Cyhalothrin & 5,514 & $45(0.82)$ & 0.26 & 0.5 & \\
\hline 28 & Cypermethrin & 5,080 & $21(0.41)$ & 0.18 & 2.0 & \\
\hline 29 & Cyproconazole & 326 & $1(0.31)$ & 0.02 & & \\
\hline 30 & Cyprodinil & 2,544 & $7(0.28)$ & 0.02 & & \\
\hline 31 & DDAC & 9 & $9(-)$ & 0.292 & & \\
\hline 32 & DDT & 1 & $1(-)$ & 0.0161 & & \\
\hline 33 & Deltamethrin & 4,415 & $78(1.77)$ & 0.05 & & \\
\hline 34 & Diazinon & 262 & $1(0.38)$ & 0.01 & & \\
\hline 35 & Dichlorvos & 17 & $1(5.88)$ & 0.154 & & \\
\hline 36 & Dicloran & 1 & $1(-)$ & 0.0155 & & \\
\hline 37 & Difenoconazole & 5,146 & $10(0.19)$ & 0.06 & 0.1 & 0.1 \\
\hline 38 & Diflubenzuron & 1,201 & $1(0.08)$ & & & \\
\hline 39 & Dimethoate & 4 & $4(-)$ & 0.05 & 1.0 & \\
\hline 40 & Dimethomorph & 2 & $2(-)$ & 0.03 & & \\
\hline 41 & Dinotefuran & 172 & $2(1.16)$ & 0.07 & 0.5 & \\
\hline 42 & Diphenylamine & 25 & $2(8)$ & 0.0139 & & \\
\hline 43 & Dithiocarbamates & 3,666 & $66(1.8)$ & 0.4 & 2.0 & 2 \\
\hline 44 & Dodine & 1,109 & $1(0.09)$ & 0.01 & & \\
\hline 45 & Endosulfan & 1,201 & $1(0.08)$ & $0.19^{\mathrm{a})}$ & 0.1 & \\
\hline 46 & Epoxiconazole & 2,312 & $10(0.48)$ & 0.02 & 0.5 & \\
\hline 47 & Ethion & 1,323 & $1(0.08)$ & 0.007 & & \\
\hline 48 & Ethoprophos & 51 & $2(3.92)$ & 0.014 & 0.02 & 0.02 \\
\hline 49 & Etofenprox & 551 & $30(5.44)$ & 0.06 & & \\
\hline 50 & Famoxadone & 236 & $1(0.42)$ & 0.01 & & \\
\hline 51 & Fenarimol & 1,323 & $1(0.08)$ & 0.1 & 0.5 & 0.2 \\
\hline 52 & Fenazaquin & 1,111 & $4(0.36)$ & 0.05 & & \\
\hline 53 & Fenbutatin oxide & 2 & $2(-)$ & 0.03 & 5.0 & 10 \\
\hline 54 & Fenhexamid & 1,326 & $4(0.3)$ & 0.05 & & \\
\hline 55 & Fenobucarb & 871 & $3(0.34)$ & 0.04 & & \\
\hline 56 & Fenpropathrin & 257 & $2(0.78)$ & 0.03 & 0.5 & \\
\hline 57 & Fenpropidin & 1,237 & $7(0.57)$ & 0.07 & & \\
\hline 58 & Fenpropimorph & 3,849 & $200(5.2)$ & 1.005 & 2.0 & 2 \\
\hline 59 & Fenuron & 50 & $1(2)$ & 0.01 & & \\
\hline 60 & Fenvalerate & 481 & $1(0.21)$ & 0.04 & 1.0 & \\
\hline 61 & Fipronil & 1,440 & $36(2.5)$ & 0.07 & & 0.005 \\
\hline 62 & Flucythrinate & 181 & $1(0.55)$ & 0.02 & & \\
\hline 63 & Fludioxonil & 1,220 & $5(0.41)$ & 0.0147 & & \\
\hline 64 & Fluopyram & 1,202 & $2(0.17)$ & 0.009 & 0.8 & \\
\hline 65 & Flusilazole & 424 & $1(0.24)$ & 0.01 & & 0.03 \\
\hline 66 & Flutriafol & 1,201 & $4(0.33)$ & & 0.3 & \\
\hline
\end{tabular}


Table 1 Continued

\begin{tabular}{|c|c|c|c|c|c|c|}
\hline \multirow{2}{*}{ No. } & \multirow{2}{*}{ Detected Pesticide } & \multirow{2}{*}{$\begin{array}{c}\text { No. of Samples } \\
\text { Analyzed }\end{array}$} & \multirow{2}{*}{$\begin{array}{l}\text { No. of Samples Detected } \\
\text { (Detection Rate \%) }\end{array}$} & \multirow{2}{*}{$\begin{array}{c}\text { Residue } \\
\text { Concentration } \\
(\mathrm{Max}, \mathrm{mg} / \mathrm{kg})\end{array}$} & \multicolumn{2}{|c|}{$\mathrm{MRLs}^{\mathrm{d})}(\mathrm{mg} / \mathrm{kg})$} \\
\hline & & & & & Korea & Codex \\
\hline 67 & Folpet & 1,323 & $1(0.08)$ & 0.02 & & \\
\hline 68 & Fosetyl-aluminium & 1 & $1(-)$ & 5 & & \\
\hline 69 & Fosthiazate & 2,311 & $3(0.13)$ & 0.02 & 0.04 & \\
\hline 70 & Hexythiazox & 3,651 & $8(0.22)$ & 0.13 & & \\
\hline 71 & Imazalil & 8,309 & $1,848(22.24)$ & $2.4^{\mathrm{c})}$ & 2.0 & 2 \\
\hline 72 & Imidacloprid & 6,780 & $37(0.55)$ & $1.013^{\mathrm{c})}$ & 0.01 & 0.05 \\
\hline 73 & Indoxacarb & 3,635 & $12(0.33)$ & 0.21 & & \\
\hline 74 & Iprodione & 3,850 & $158(4.1)$ & $2.383^{\mathrm{a})}$ & 0.02 & \\
\hline 75 & Kresoxim-methyl & 3,857 & $17(0.44)$ & 0.19 & & \\
\hline 76 & Malathion & 387 & $2(0.52)$ & 0.05 & & \\
\hline 77 & Metalaxyl & 180 & $2(1.11)$ & 0.0176 & & \\
\hline 78 & Methidathion & 1,323 & $1(0.08)$ & 0.01 & & \\
\hline 79 & Methiocarb & 1,201 & $1(0.08)$ & & & \\
\hline 80 & Methomyl & 528 & $5(0.95)$ & 0.09 & & \\
\hline 81 & Methyl bromide & 118 & $26(22.03)$ & 4 & 20 & \\
\hline 82 & Monocrotophos & 1,100 & $1(0.09)$ & 0.03 & & \\
\hline 83 & Myclobutanil & 5,913 & $232(3.92)$ & 0.49 & 4.0 & \\
\hline 84 & Oxamyl & 4 & $4(-)$ & 0.028 & 0.2 & \\
\hline 85 & Paclobutrazol & 1,323 & $1(0.08)$ & 0.242 & & \\
\hline 86 & Penconazole & 2 & $2(-)$ & 0.0131 & & \\
\hline 87 & Permethrin & 291 & $2(0.69)$ & 0.01 & 5.0 & \\
\hline 88 & Phosalone & 2,433 & $3(0.12)$ & 0.03 & & \\
\hline 89 & Phosmet & 11 & $1(9.09)$ & 0.01 & & \\
\hline 90 & Pretilachlor & 97 & $12(12.37)$ & 0.72 & & \\
\hline 91 & Prochloraz & 1,282 & $11(0.86)$ & 0.25 & 5.0 & 7 \\
\hline 92 & Procymidone & 472 & $1(0.21)$ & 0.01 & & \\
\hline 93 & Propamocarb & 1,110 & $2(0.18)$ & 0.03 & & \\
\hline 94 & Propiconazole & 1,447 & $4(0.28)$ & 0.02 & 0.1 & 0.1 \\
\hline 95 & Pyraclostrobin & 1 & $1(-)$ & 0.009 & 0.02 & 0.02 \\
\hline 96 & Pyridaben & 1 & $1(-)$ & 0.0132 & & \\
\hline 97 & Pyrimethanil & 6,037 & $34(0.56)$ & 0.1 & 0.1 & 0.1 \\
\hline 98 & Pyriproxyfen & 2,538 & $4(0.16)$ & 0.03 & & \\
\hline 99 & Spinosad & 2,780 & $12(0.43)$ & 0.033 & & \\
\hline 100 & Spiromesifen & 1,297 & $5(0.39)$ & 0.01 & & \\
\hline 101 & Spiroxamine & 3,671 & $9(0.25)$ & 0.0138 & 3.0 & \\
\hline 102 & Tebuconazole & 4,835 & $12(0.25)$ & $0.06^{\mathrm{a})}$ & 0.05 & 1.5 \\
\hline 103 & Thiabendazole & 9,197 & $977(10.62)$ & $3.5^{\mathrm{a})}$ & 3.0 & 5 \\
\hline 104 & Thiamethoxam & 4,229 & $78(1.84)$ & $0.06^{\mathrm{c})}$ & 0.02 & 0.02 \\
\hline 105 & Tolylfluanid & 1 & $1(-)$ & 0.0188 & & \\
\hline 106 & Triadimenol & 2,367 & $14(0.59)$ & 0.09 & & 1 \\
\hline 107 & Tribufos & 59 & $1(1.69)$ & 0.01 & & \\
\hline 108 & Tridemorph & 194 & $3(1.55)$ & 0.017 & 1.0 & \\
\hline \multirow[t]{2}{*}{109} & Trifloxystrobin & 1 & $1(-)$ & $0.071^{\mathrm{c})}$ & 0.05 & 0.05 \\
\hline & & 206,894 & $9,483(4.58)$ & & & \\
\hline
\end{tabular}

${ }^{a)}$ Residues exceeding Korean MRLs, ${ }^{\text {b) }}$ Residues exceeding Codex MRLs, ${ }^{c}$ Residues exceeding Korean \& Codex MRLs, ${ }^{\text {d) }}$ As of February 2019 
터 PLS가 시행되고 있으므로, 외국 정부 및 농약회사로부터 IT 설정 요청을 받아 계속 증가되고 있는 실정이다.

각 검사국별로 바나나에서 검출된 농약의 종류는 Table 2 와 같다. $\mathrm{EU}$ 에서 가장 많은 85 종 농약이 검출되었고, 일본, 미국, 영국 및 우리나라는 각각 $57,23,18$ 및 8 종 농약이 검출되었 다. Azoxystrobin, bifenthrin 및 chlorpyrifos는 모든 국가의 모 니터링에서 검출되었다. Boscalid, buprofezin, fenpropimorph, imazalil, iprodione, myclobutanil 및 thiabendazole 농약은 각국 모니터링에서 빈번히 검출되는 성분이었다. 열대 및 아열대 기 후 지역에서 재배되는 바나나는 각국에서 주로 수입을 통해 유 통되는 농산물이므로 저장 및 유통과정 중 병해충을 방제하기 위해 post-harvest 농약을 처리하게 된다. Azoxystrobin, chlorpyrifos, imazalil 및 thiabendazole 등이 post-harvest 농약 으로 사용되고 있으므로, 본 연구 결과에서 검출 빈도가 높은 것으로 판단되었다. 유 등은 생즙 원료 오렌지 및 감귤에서 post-harvest 농약인 imazalil 및 chlorpyrifos의 검출을 확인하였 다[34]. 황 등도 수입 과일에 살포된 수확 후 처리 농약의 경 시적 변화에서 chlorpyrifos는 처리 직후 과일 전체에서 0.4$2.2 \mathrm{mg} / \mathrm{kg}$, 과육에서 ND-0.32 mg/kg으로 조사 되었고, 4주 후에 는 과일 전체에서 $0.3-0.9 \mathrm{mg} / \mathrm{kg}$, 과육에서 $\mathrm{ND}-0.02 \mathrm{mg} / \mathrm{kg}$ 으로 조사 되었다고 보고하였다[35].

잔류농약 모니터링 자료는 일일추정섭취량(Estimated Daily Intake, EDI) 평가에 활용되고 있으며 위해평가 시 껍질째 농약 이 검출된 자료를 활용하고 있다[26]. 한국의 2015년 모니터링 에서 바나나 껍질을 미포함한 잔류농약 검사를 실시 하였고 그 결과, 껍질을 제거한 후 농약 검출률은 $23.8 \%$ 로 껍질째 분석한 검출률 $57.1 \%$ 보다 감소 되었다[26]. 정 등도 과피 제거 전후에 따른 감귤류에 대하여 평균 $91.6 \%$ 의 잔류농약 제거 효과가 있 다고 보고하였다[36]. 또한, 조 등에 의해 가식부 및 비가식부
에 대한 분리 실험이 실시 되었고, 잔류량 대부분이 과피에 잔 존함을 보고하였다[37]. 바나나는 껍질을 제거한 후 섭취하게 되므로 위해평가에서 껍질 제거 계수(Peeling Factor)를 고려할 필요도 있다고 판단된다.

각국의 잔류농약 모니터링 결과에서 검출된 농약을 연도별로 검사 건수에 대한 검출 건수로 명시하여 Table 3에 나타내었다. 2007년부터 2018년까지 바나나에 대한 농약의 검출률은 3.36$7.58 \%$ 범위였으며, 총 12 년간 검출률 평균은 $4.58 \%$ 였다. 20162018 년의 검출률은 $6.33-7.58 \%$ 로 12 년간 평균 검출률보다 높게 나타났는데, 이 결과는 부적합 자료 및 모니터링 보고서를 발 표한 일부 국가의 검출 자료만이 수집되었기 때문으로 판단된다. 각국에서 실시한 바나나의 잔류농약 모니터링에서 검출된 총 109종 농약 중 2007-2018년 동안 년도별 검출된 농약 수는 955종이었다. 9개 년도 이상 검출된 농약은 azoxystrobin, bifenthrin, buprofezin, carbendazim, chlorfenapyr, chlorpyrifos, clothianidin, cypermethrin, deltamethrin, fenpropimorph, imazalil, imidacloprid, iprodione, myclobutanil, thiabendazole 및 thiamethoxam 16 종이었다. 이 중 azoxystrobin 및 bifenthrin은 매년 검출되었다.

Azoxystrobin은 미토콘드리아 전자 전달 체계 중 복합체 III 의 퀴논에 결합하여 전자 전달을 저해하여 ATP 생성을 방해하 는 기작을 가진 사용 스펙트럼이 넓은 살균제이다[38]. 우리나 라에서는 벼의 도열병, 멸구, 흰잎마름병 및 이화병나방 등의 다양한 병해충 방제에 사용하도록 등록되어 있으며, 고추, 상추 및 수박 등의 흰가루병, 인삼의 점무늬병과 탄저병 예방 및 치 료 효과를 동시에 보인다[39]. 우리나라에는 가지, 감귤 및 바 나나 등 99종의 식품에 이 농약에 대한 잔류허용기준이 설정되 었다[27].

Bifenthrin은 접촉 및 식독으로 나트륨 채널에 간섭하여 신경 계에 영향을 주는 피레스로이드계 살충제로 $\mathrm{K}_{\mathrm{ow}}$ 값은 6.0 이상

Table 2 List of residual pesticides detected in bananas by country among global residual pesticide monitoring results from 2007 to 2018

\begin{tabular}{cl}
\hline \hline Country (No.) $^{\text {a) }}$ & \multicolumn{1}{c}{ Detected Pesticides } \\
& 2-Phenylphenol, Acetamiprid, Acrinathrin, Azinphos-methyl, Azoxystrobin, Bifenthrin, Biphenyl, Bitertanol, Boscalid, \\
& Bromopropylate, Bupirimate, Buprofezin, Carbaryl, Carbendazim, Chlorothalonil, Chlorpropham, Chlorpyrifos, Chlorpyrifos-methyl, \\
& Clofentezine, Cyfluthrin, Cyhalothrin, Cypermethrin, Cyprodinil, DDAC, DDT, Deltamethrin, Dicloran, Difenoconazole, \\
EU & Diflubenzuron, Dimethoate, Dimethomorph, Diphenylamine, Dithiocarbamates, Dodine, Endosulfan, Epoxiconazole, Ethion, \\
(85) & Ethoprophos, Fenarimol, Fenazaquin, Fenbutatin oxide, Fenhexamid, Fenpropidin, Fenpropimorph, Fipronil, Fludioxonil, Fluopyram, \\
& Flutriafol, Folpet, Fosetyl-aluminium, Fosthiazate, Hexythiazox, Imazalil, Imidacloprid, Indoxacarb, Iprodione, Kresoxim-methyl, \\
& Malathion, Metalaxyl, Methidathion, Methiocarb, Methomyl, Monocrotophos, Myclobutanil, Oxamyl, Paclobutrazol, Penconazole, \\
& Phosalone, Prochloraz, Propamocarb, Propiconazole, Pyraclostrobin, Pyridaben, Pyrimethanil, Pyriproxyfen, Spinosad, Spiromesifen, \\
& Spiroxamine, Tebuconazole, Thiabendazole, Thiamethoxam, Tolylfluanid, Triadimenol, Tridemorph, Trifloxystrobin.
\end{tabular}

${ }^{\mathrm{a}}$ Numbers of pesticides detected 
으로 물에 잘 녹지 않는다[38]. 진딧물, 응애, 노린재, 파밤나방, 목화바둑명나방, 배추좀나방 및 잎말이나방 등을 방제하기 위하 여 수박, 사과, 수수, 시금치, 오이, 유채 및 참깨 등에 사용하 도록 bifenthrin은 우리나라에 등록되어 있다[40].

포루투갈산 바나나에서 검출된 endosulfan은 2015년 EU 모 니터링에서만 보고되었다. 토양에 잔류된 endosulfan이 작물로 흡수이행 되어 나타난 결과로 판단된다. Endosulfan은 과거 낮 은 농도에서도 탁월한 살충력을 나타내어 응애와 담배나방 방 제에 흔히 사용되었던 유기염소계 살충제였으나 높은 생물농축 성과 독성, 그리고 장거리 이동성으로 인해 잔류성유기오염물질 (Persistent Organic Pollutants, POPs)로 규정되어 국제적으로 생산 및 사용이 금지되었다[41,42]. 그러나 인도, 중국 및 여러 개발도상국에서 여전히 사용되고 있으며 토양, 퇴적층, 민물, 해 수, 대기 등 다양한 환경에서 최근까지 검출되고 있다[43]. 우 리나라는 2011년에 endosulfan의 농약 등록을 취소하였고, 2015 년에 $\mathrm{POPs}$ 으로 등록하여 endosulfan에 대한 관리를 강화하였다 [44].

본 연구에서 정확한 원산지를 알 수 있는 자료를 활용하여 조사된 바나나 원산지는 26(프랑스의 해외 주인 과들루프 포함) 개국이었으며, 검출 농약 48 종에 대한 24,330 건 검사에서 검출 된 2,143건을 원산지별 농약 검출현황으로 Table 4에 나타내었 다. 원산지별 검출현황은 각국의 자료 중 원산지 미상으로 표
기한 검출 농약 79 종에 대한 검출 4,169 건, 한국의 모니터링 자 료 중 검출된 8 종 농약에 대한 39건 및 일본의 모니터링 자료 중 원산지가 표시된 chlorfenapyr, chlorpyrifos, cypermethrin, fipronil와 imidacloprid의 검출 자료를 제외한 57 종에 대한 검출 3,132 건을 원산지를 알 수 없어서 제외하였다. 다만, 제외된 100 종 농약 중 39 종은 원산지를 알 수 있는 농약과 중복되었다.

다수 농약이 검출되는 바나나의 원산지는 코스타리카, 에콰 도르, 콜롬비아 및 캐나다로 나타났다. 코스타리카산에서 azoxystrobin, bifenthrin, boscalid, buprofezin, chlorpyrifos, dithiocarbamates, ethoprophos, fenpropimorph, imazalil, myclobutanil, oxamyl, pyrimethanil, pyriproxyfen 및 thiabendazole 14종 농 약이 검출되었고, 에콰도르산에서 bifenthrin, biphenyl, carbaryl, carbendazim, chlorpyrifos, DDAC, diphenylamine, fenpropimorph, fosetyl-aluminium, imazalil, thiabendazole, 및 tridemorph 12종 농약이 검출되었다. 콜롬비아를 원산지로 하는 바나나에서 azoxystrobin, boscalid 및 trifloxystrobin 등 11종 농약이 검출 되었다. 캐나다가 원산지인 바나나는 바나나를 포함한 혼합 과 일 제품을 미국이 캐나다에서 수입하며 검출된 농약 때문에 10 종이 검출되었다. 인디아, 페루 및 수리남에서는 각각 carbendazim, fipronil 및 iprodione 1종 농약씩만 검출되었다.

검출된 농약 중 imazalil은 벨리즈, 브라질, 카메룬, 콜롬비아, 코스타리카, 코트디부아르, 도미니카공화국, 에콰도르, 프랑스,

Table 3 Tendency to detect residual pesticide in bananas per year among global residual pesticide monitoring results from 2007 to 2018

\begin{tabular}{|c|c|c|c|c|c|c|c|c|c|c|c|c|}
\hline \multirow{2}{*}{ Pesticide } & \multicolumn{12}{|c|}{ Year } \\
\hline & 2007 & 2008 & 2009 & 2010 & 2011 & 2012 & 2013 & 2014 & 2015 & 2016 & 2017 & 2018 \\
\hline 2-Phenylphenol & - & - & - & - & - & $2 / 1109^{a)}$ & $1 / 1$ & - & $3 / 1201$ & - & - & - \\
\hline Acetamiprid & - & - & $1 / 306$ & - & $1 / 327$ & - & $1 / 304$ & $1 / 331$ & $2 / 1201$ & - & - & - \\
\hline Acibenzolar-S-methyl & - & - & $1 / 229$ & - & - & - & - & - & - & - & - & - \\
\hline Acrinathrin & - & - & - & $1 / 1$ & $1 / 1$ & $37 / 1111$ & $1 / 1$ & - & $34 / 1201$ & - & - & - \\
\hline Atrazine & - & - & - & - & - & - & $1 / 327$ & - & - & - & - & - \\
\hline Azinphos-methyl & - & - & - & $1 / 1$ & - & - & - & - & - & - & - & - \\
\hline Azoxystrobin & $20 / 269$ & $29 / 267$ & $115 / 1713$ & $28 / 370$ & $16 / 206$ & $355 / 1664$ & $60 / 434$ & $55 / 341$ & $480 / 2758$ & $16 / 250$ & $13 / 176$ & $15 / 270$ \\
\hline Bifenthrin & $7 / 333$ & $4 / 350$ & $89 / 1803$ & $22 / 427$ & $28 / 286$ & $135 / 1528$ & $30 / 436$ & $32 / 347$ & $271 / 2227$ & $11 / 148$ & $2 / 26$ & $9 / 162$ \\
\hline Biphenyl & - & - & - & - & - & $1 / 35$ & $1 / 1$ & - & - & - & - & - \\
\hline Bitertanol & - & $2 / 210$ & $2 / 378$ & $5 / 196$ & $5 / 185$ & $52 / 1524$ & $3 / 353$ & $2 / 318$ & $1 / 579$ & - & - & - \\
\hline Boscalid & - & - & $1 / 1323$ & $1 / 1$ & - & $3 / 1355$ & $1 / 1$ & $2 / 221$ & $32 / 1592$ & $3 / 50$ & - & $7 / 126$ \\
\hline Bromophos-methyl & - & - & - & - & - & - & - & - & $1 / 110$ & - & - & - \\
\hline Bromopropylate & - & - & $2 / 1659$ & - & - & - & - & - & - & - & - & - \\
\hline Bupirimate & - & - & $1 / 1323$ & - & - & - & $1 / 1$ & - & - & - & - & - \\
\hline Buprofezin & - & - & $2 / 1615$ & $1 / 1$ & $1 / 1$ & $2 / 1109$ & $1 / 1$ & $5 / 402$ & $157 / 1734$ & $6 / 67$ & $2 / 26$ & $8 / 144$ \\
\hline Captan & - & - & - & - & - & - & - & $3 / 51$ & - & - & - & - \\
\hline Carbaryl & - & - & - & $2 / 348$ & - & $1 / 305$ & $1 / 1$ & - & $1 / 1$ & - & - & - \\
\hline Carbendazim & $5 / 24$ & $9 / 22$ & $524 / 2662$ & $8 / 24$ & $3 / 11$ & $9 / 120$ & $7 / 43$ & $9 / 48$ & $5 / 1258$ & - & - & - \\
\hline Chlorfenapyr & $15 / 368$ & $14 / 356$ & $17 / 507$ & $11 / 464$ & $12 / 452$ & $13 / 418$ & $17 / 378$ & $18 / 472$ & $14 / 423$ & - & - & - \\
\hline Chlorothalonil & $2 / 51$ & $1 / 29$ & $2 / 1343$ & $1 / 1$ & $1 / 1$ & $1 / 1$ & $1 / 1$ & $1 / 17$ & - & - & - & - \\
\hline Chlorpropham & - & - & - & - & $1 / 1$ & - & $1 / 1$ & - & - & - & - & - \\
\hline Chlorpyrifos & $115 / 452$ & $150 / 447$ & $344 / 1925$ & $168 / 617$ & $226 / 634$ & $447 / 1884$ & $218 / 779$ & $242 / 582$ & $426 / 2082$ & $4 / 46$ & - & $4 / 72$ \\
\hline Chlorpyrifos-methyl & $1 / 321$ & - & - & - & - & $1 / 1109$ & - & - & $5 / 1201$ & - & - & - \\
\hline Clofentezine & - & - & - & $1 / 1$ & - & $1 / 1109$ & - & - & - & - & - & - \\
\hline Clothianidin & $2 / 94$ & $7 / 187$ & $3 / 59$ & $5 / 88$ & $3 / 77$ & $2 / 76$ & $3 / 100$ & $2 / 82$ & $2 / 91$ & - & - & - \\
\hline
\end{tabular}


Table 3 Continued

\begin{tabular}{|c|c|c|c|c|c|c|c|c|c|c|c|c|}
\hline \multirow{2}{*}{ Pesticide } & \multicolumn{12}{|c|}{ Year } \\
\hline & 2007 & 2008 & 2009 & 2010 & 2011 & 2012 & 2013 & 2014 & 2015 & 2016 & 2017 & 2018 \\
\hline Cyfluthrin & - & - & - & $1 / 1$ & $1 / 1$ & - & - & - & - & - & - & - \\
\hline Cyhalothrin & - & $5 / 387$ & $4 / 1852$ & $6 / 480$ & $1 / 1$ & $5 / 1532$ & $4 / 376$ & $16 / 481$ & $4 / 405$ & - & - & - \\
\hline Cypermethrin & $4 / 400$ & - & $1 / 572$ & $1 / 1$ & $2 / 472$ & $2 / 1551$ & $2 / 2$ & $4 / 463$ & $4 / 1618$ & $1 / 1$ & - & - \\
\hline Cyproconazole & - & - & $1 / 326$ & - & - & - & - & - & - & - & - & - \\
\hline Cyprodinil & - & - & $1 / 1323$ & $1 / 1$ & - & $1 / 1$ & $1 / 1$ & $1 / 17$ & $2 / 1201$ & - & - & - \\
\hline DDAC & - & - & - & - & - & $9 / 9$ & - & - & - & - & - & - \\
\hline DDT & - & - & - & - & $1 / 1$ & - & - & - & - & - & - & - \\
\hline Deltamethrin & $4 / 363$ & $5 / 329$ & $5 / 417$ & $6 / 364$ & $9 / 365$ & $6 / 1450$ & $14 / 308$ & $17 / 430$ & $12 / 389$ & - & - & - \\
\hline Diazinon & - & - & - & $1 / 262$ & - & - & - & - & - & - & - & - \\
\hline Dichlorvos & - & - & - & - & - & - & - & $1 / 17$ & - & - & - & - \\
\hline Dicloran & - & - & - & $1 / 1$ & - & - & - & - & - & - & - & - \\
\hline Difenoconazole & $1 / 320$ & $1 / 329$ & $3 / 1778$ & - & $1 / 1$ & $3 / 1517$ & - & - & $1 / 1201$ & - & - & - \\
\hline Diflubenzuron & - & - & - & - & - & - & - & - & $1 / 1201$ & - & - & - \\
\hline Dimethoate & - & - & - & $1 / 1$ & $1 / 1$ & - & $1 / 1$ & $1 / 1$ & - & - & - & - \\
\hline Dimethomorph & - & - & - & $1 / 1$ & - & - & - & - & $1 / 1$ & - & - & - \\
\hline Dinotefuran & - & - & $2 / 172$ & - & - & - & - & - & - & - & - & - \\
\hline Diphenylamine & - & - & - & $1 / 24$ & $1 / 1$ & - & - & - & - & - & - & - \\
\hline Dithiocarbamates & - & - & $1 / 1323$ & $1 / 1$ & $1 / 1$ & $36 / 1109$ & $1 / 1$ & - & $24 / 1201$ & $1 / 17$ & $1 / 13$ & - \\
\hline Dodine & - & - & - & - & - & $1 / 1109$ & - & - & - & - & - & - \\
\hline Endosulfan & - & - & - & - & - & - & - & - & $1 / 1201$ & - & - & - \\
\hline Epoxiconazole & - & - & - & $1 / 1$ & $1 / 1$ & $7 / 1109$ & $1 / 1$ & - & $1 / 1201$ & - & - & - \\
\hline Ethion & - & - & $1 / 1323$ & - & - & - & - & - & - & - & - & - \\
\hline Ethoprophos & - & - & - & - & - & - & $1 / 1$ & - & $1 / 50$ & - & - & - \\
\hline Etofenprox & - & - & - & - & - & - & - & $19 / 223$ & $11 / 328$ & - & - & - \\
\hline Famoxadone & - & - & $1 / 236$ & - & - & - & - & - & - & - & - & - \\
\hline Fenarimol & - & - & $1 / 1323$ & - & - & - & - & - & - & - & - & - \\
\hline Fenazaquin & - & - & - & $1 / 1$ & $1 / 1$ & $2 / 1109$ & - & - & - & - & - & - \\
\hline Fenbutatin oxide & - & - & - & - & $1 / 1$ & $1 / 1$ & - & - & - & - & - & - \\
\hline Fenhexamid & - & - & $1 / 1323$ & - & $1 / 1$ & $1 / 1$ & $1 / 1$ & - & - & - & - & - \\
\hline Fenobucarb & - & $1 / 295$ & $1 / 250$ & $1 / 326$ & - & - & - & - & - & - & - & - \\
\hline Fenpropathrin & - & - & - & - & $1 / 240$ & - & - & $1 / 17$ & - & - & - & - \\
\hline Fenpropidin & - & - & - & - & - & - & - & - & $5 / 1201$ & - & - & $2 / 36$ \\
\hline Fenpropimorph & - & $1 / 146$ & $1 / 316$ & $1 / 1$ & $1 / 1$ & $55 / 1319$ & $2 / 249$ & $1 / 17$ & $123 / 1585$ & $12 / 171$ & $2 / 26$ & $1 / 18$ \\
\hline Fenuron & - & - & - & - & - & - & - & - & $1 / 50$ & - & - & - \\
\hline Fenvalerate & - & - & - & - & - & - & - & $1 / 481$ & - & - & - & - \\
\hline Fipronil & - & $1 / 147$ & $2 / 319$ & - & $1 / 1$ & $1 / 185$ & $11 / 310$ & $6 / 243$ & $2 / 223$ & - & - & $12 / 12$ \\
\hline Flucythrinate & - & - & - & $1 / 181$ & - & - & - & - & - & - & - & - \\
\hline Fludioxonil & - & - & - & $1 / 1$ & - & $1 / 1$ & - & $1 / 17$ & $2 / 1201$ & - & - & - \\
\hline Fluopyram & - & - & - & - & - & - & $1 / 1$ & - & $1 / 1201$ & - & - & - \\
\hline Flusilazole & - & - & - & - & $1 / 424$ & - & - & - & - & - & - & - \\
\hline Flutriafol & - & - & - & - & - & - & - & - & $4 / 1201$ & - & - & - \\
\hline Folpet & - & - & $1 / 1323$ & - & - & - & - & - & - & - & - & - \\
\hline Fosetyl-aluminium & - & - & - & - & - & - & - & $1 / 1$ & - & - & - & - \\
\hline Fosthiazate & - & - & - & - & - & $1 / 1109$ & $1 / 1$ & - & $1 / 1201$ & - & - & - \\
\hline Hexythiazox & - & - & $1 / 1323$ & - & $1 / 1$ & $3 / 1109$ & - & $1 / 17$ & $2 / 1201$ & - & - & - \\
\hline Imazalil & - & $1 / 138$ & $593 / 1478$ & $9 / 219$ & $5 / 146$ & $572 / 1773$ & $10 / 502$ & $16 / 444$ & $590 / 2829$ & $23 / 333$ & $17 / 231$ & $12 / 216$ \\
\hline
\end{tabular}


Table 3 Continued

\begin{tabular}{|c|c|c|c|c|c|c|c|c|c|c|c|c|}
\hline \multirow{2}{*}{ Pesticide } & \multicolumn{12}{|c|}{ Year } \\
\hline & 2007 & 2008 & 2009 & 2010 & 2011 & 2012 & 2013 & 2014 & 2015 & 2016 & 2017 & 2018 \\
\hline Imidacloprid & $4 / 243$ & $4 / 238$ & $2 / 1713$ & $2 / 398$ & $5 / 359$ & $5 / 1484$ & $5 / 296$ & $3 / 360$ & $6 / 1688$ & - & $1 / 1$ & - \\
\hline Indoxacarb & - & - & $1 / 1323$ & $1 / 1$ & $1 / 1$ & $4 / 1109$ & - & - & $5 / 1201$ & - & - & - \\
\hline Iprodione & $41 / 280$ & $49 / 283$ & $37 / 1620$ & $2 / 81$ & $5 / 83$ & $6 / 123$ & $12 / 99$ & $4 / 47$ & $2 / 1234$ & - & - & - \\
\hline Kresoxim-methyl & $1 / 339$ & $1 / 349$ & $1 / 1323$ & $5 / 388$ & $2 / 281$ & $3 / 422$ & $3 / 391$ & $1 / 364$ & - & - & - & - \\
\hline Malathion & - & - & - & - & - & $1 / 1$ & - & $1 / 386$ & - & - & - & - \\
\hline Metalaxyl & $1 / 179$ & - & - & $1 / 1$ & - & - & - & - & - & - & - & - \\
\hline Methidathion & - & - & $1 / 1323$ & - & - & - & - & - & - & - & - & - \\
\hline Methiocarb & - & - & - & - & - & - & - & - & $1 / 1201$ & - & - & - \\
\hline Methomyl & - & - & - & $2 / 222$ & $1 / 113$ & - & - & $1 / 1$ & $1 / 192$ & - & - & - \\
\hline Methyl bromide & $2 / 13$ & - & $2 / 24$ & $2 / 11$ & $3 / 10$ & $2 / 10$ & $2 / 9$ & $6 / 17$ & $7 / 24$ & - & - & - \\
\hline Monocrotophos & - & - & $1 / 1100$ & - & - & - & - & - & - & - & - & - \\
\hline Myclobutanil & - & - & $1 / 1323$ & $1 / 1$ & $1 / 1$ & $73 / 1565$ & $3 / 421$ & $5 / 501$ & $134 / 1890$ & $7 / 109$ & $5 / 66$ & $2 / 36$ \\
\hline Oxamyl & - & - & - & - & $1 / 1$ & - & $1 / 1$ & - & - & $2 / 2$ & - & - \\
\hline Paclobutrazol & - & - & $1 / 1323$ & - & - & - & - & - & - & - & - & - \\
\hline Penconazole & - & - & - & $1 / 1$ & $1 / 1$ & - & - & - & - & - & - & - \\
\hline Permethrin & - & - & - & - & $1 / 273$ & - & - & - & - & - & - & $1 / 18$ \\
\hline Phosalone & - & - & $1 / 1323$ & - & $1 / 1$ & $1 / 1109$ & - & - & - & - & - & - \\
\hline Phosmet & - & - & - & - & - & - & - & - & - & $1 / 11$ & - & - \\
\hline Pretilachlor & - & $4 / 23$ & $6 / 34$ & $2 / 40$ & - & - & - & - & - & - & - & - \\
\hline Prochloraz & - & - & - & - & $4 / 37$ & $5 / 1182$ & $1 / 44$ & $1 / 19$ & - & - & - & - \\
\hline Procymidone & - & - & - & $1 / 472$ & - & - & - & - & - & - & - & - \\
\hline Propamocarb & - & - & - & $1 / 1$ & - & $1 / 1109$ & - & - & - & - & - & - \\
\hline Propiconazole & - & $1 / 337$ & - & $1 / 1$ & - & $2 / 1109$ & - & - & - & - & - & - \\
\hline Pyraclostrobin & - & - & - & - & - & - & $1 / 1$ & - & - & - & - & - \\
\hline Pyridaben & - & - & - & $1 / 1$ & - & - & - & - & - & - & - & - \\
\hline Pyrimethanil & - & - & $2 / 1774$ & $2 / 555$ & $2 / 637$ & $7 / 1524$ & $2 / 338$ & - & $19 / 1209$ & - & - & - \\
\hline Pyriproxyfen & - & - & $1 / 1323$ & $1 / 1$ & - & - & - & - & $2 / 1214$ & - & - & - \\
\hline Spinosad & - & $2 / 93$ & - & $1 / 152$ & - & $3 / 1110$ & $1 / 189$ & - & $4 / 1218$ & - & - & $1 / 18$ \\
\hline Spiromesifen & - & $1 / 35$ & $2 / 27$ & $1 / 34$ & - & - & - & - & $1 / 1201$ & - & - & - \\
\hline Spiroxamine & - & - & $1 / 1323$ & - & $1 / 1$ & $3 / 1145$ & $1 / 1$ & - & $3 / 1201$ & - & - & - \\
\hline Tebuconazole & $1 / 375$ & $3 / 382$ & $1 / 544$ & $1 / 477$ & $1 / 479$ & $2 / 454$ & $1 / 433$ & - & $2 / 1691$ & - & - & - \\
\hline Thiabendazole & - & $5 / 270$ & $2 / 1727$ & $11 / 454$ & $8 / 430$ & $303 / 1915$ & $7 / 447$ & $13 / 376$ & $580 / 2851$ & $20 / 264$ & $9 / 121$ & $19 / 342$ \\
\hline Thiamethoxam & $10 / 252$ & $10 / 248$ & $15 / 372$ & $12 / 381$ & $7 / 336$ & $8 / 358$ & $5 / 284$ & $3 / 345$ & $7 / 1641$ & $1 / 12$ & - & - \\
\hline Tolylfluanid & - & - & - & - & $1 / 1$ & - & - & - & - & - & - & - \\
\hline Triadimenol & $1 / 231$ & - & $1 / 339$ & $3 / 175$ & $3 / 189$ & $1 / 1109$ & $5 / 324$ & - & - & - & - & - \\
\hline Tribufos & - & - & - & - & - & - & - & - & $1 / 59$ & - & - & - \\
\hline Tridemorph & - & - & - & - & - & $1 / 192$ & - & - & $2 / 2$ & - & - & - \\
\hline Trifloxystrobin & - & - & - & - & - & - & - & - & $1 / 1$ & - & - & - \\
\hline No. of Detected Pesticides & 19 & 25 & 51 & 54 & 50 & 53 & 47 & 37 & 55 & 14 & 9 & 13 \\
\hline 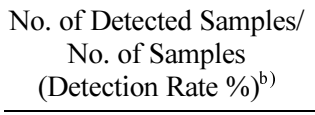 & $\begin{array}{c}237 / \\
4907 \\
(4.83)\end{array}$ & $\begin{array}{l}311 / \\
5897 \\
(5.27) \\
\end{array}$ & $\begin{array}{l}1804 / \\
53680 \\
(3.36) \\
\end{array}$ & $\begin{array}{c}346 / \\
8255 \\
(4.19) \\
\end{array}$ & $\begin{array}{c}379 / \\
7077 \\
(5.36) \\
\end{array}$ & $\begin{array}{l}2200 / \\
47481 \\
(4.63) \\
\end{array}$ & $\begin{array}{c}450 / \\
8196 \\
(5.49) \\
\end{array}$ & $\begin{array}{c}497 / \\
8497 \\
(5.85) \\
\end{array}$ & $\begin{array}{l}3006 / \\
59267 \\
(5.07) \\
\end{array}$ & $\begin{array}{c}108 / \\
1481 \\
(7.29) \\
\end{array}$ & $\begin{array}{c}52 / \\
686 \\
(7.58) \\
\end{array}$ & $\begin{array}{c}93 / \\
1470 \\
(6.33) \\
\end{array}$ \\
\hline Reporting Country & Japan & Japan & $\begin{array}{c}\text { Japan } \\
\text { EU }\end{array}$ & $\begin{array}{l}\text { Japan } \\
\text { EU } \\
\text { USA }\end{array}$ & $\begin{array}{c}\text { Japan } \\
\text { EU } \\
\text { USA }\end{array}$ & $\begin{array}{c}\text { Japan } \\
\text { EU } \\
\text { USA } \\
\text { UK } \\
\text { Korea }\end{array}$ & $\begin{array}{c}\text { Japan } \\
\text { EU } \\
\text { USA } \\
\text { Korea }\end{array}$ & $\begin{array}{c}\text { Japan } \\
\text { EU } \\
\text { USA }\end{array}$ & $\begin{array}{c}\text { Japan } \\
\text { EU } \\
\text { USA } \\
\text { UK } \\
\text { Korea }\end{array}$ & $\begin{array}{c}\text { Japan } \\
\text { EU } \\
\text { USA } \\
\text { UK } \\
\text { Korea }\end{array}$ & $\begin{array}{l}\text { Japan } \\
\text { EU } \\
\text { UK }\end{array}$ & $\begin{array}{c}\text { Japan } \\
\text { UK }\end{array}$ \\
\hline
\end{tabular}

a) No. of Detected Samples/No. of Samples, ${ }^{\text {b) }}$ Total No. of Detected Samples per Year /Total No. of Samples per Year 
가나, 과테말라, 온두라스, 멕시코, 파나마, 세인트루시아 및 윈 드워드제도산 바나나에서 검출되어 가장 많은 원산지에서 검출 되었다. Chlorpyrifos는 13개, azoxystrobin 및 thiabendazole은 11 개 원산지에서 검출되었다.

Table 4 Major detected pesticides in bananas by the country of origin among global residual pesticide monitoring results from 2007 to 2018

\begin{tabular}{|c|c|c|c|c|}
\hline $\begin{array}{l}\text { Origin of } \\
\text { Bananas }\end{array}$ & $\begin{array}{l}\text { Detected } \\
\text { esticides }\end{array}$ & $\begin{array}{c}\text { No. of } \\
\text { Samples } \\
\text { Analyzed }\end{array}$ & $\begin{array}{c}\text { No. of } \\
\text { Samples } \\
\text { Detected }\end{array}$ & $\begin{array}{c}\text { Residue } \\
\text { Concentration } \\
(\mathrm{mg} / \mathrm{kg})\end{array}$ \\
\hline \multirow{6}{*}{ Belize } & Azoxystrobin & 132 & 14 & $0.07-0.7$ \\
\hline & Chlorpyrifos & 22 & 5 & $0.01-0.1$ \\
\hline & Imazalil & 113 & 12 & $0.02-1.2$ \\
\hline & Myclobutanil & 18 & 1 & 0.02 \\
\hline & Thiabendazole & 18 & 1 & 0.2 \\
\hline & 5 & 303 & 33 & \\
\hline \multirow{4}{*}{ Brazil } & Bifenthrin & 18 & 1 & $0.01-0.01$ \\
\hline & Imazalil & 19 & 2 & $0.09-0.3$ \\
\hline & Thiabendazole & 19 & 2 & $0.07-0.2$ \\
\hline & 3 & 56 & 5 & \\
\hline \multirow{6}{*}{ Cameroon } & Azoxystrobin & 93 & 5 & $0.07-0.5$ \\
\hline & Bitertanol & 3 & 3 & $0.2-0.5$ \\
\hline & Chlorpyrifos & 1 & 1 & 0.02 \\
\hline & Fenpropimorph & 1 & 1 & 0.02 \\
\hline & Imazalil & 61 & 13 & $0.03-0.52$ \\
\hline & 5 & 159 & 23 & \\
\hline \multirow{11}{*}{ Canada } & Bifenthrin & 17 & 1 & 0.124 \\
\hline & Captan & 34 & 2 & 0.011 \\
\hline & Carbendazim & 34 & 2 & $0.012-0.013$ \\
\hline & Chlorothalonil & 17 & 1 & 0.01 \\
\hline & Cyprodinil & 17 & 1 & 0.012 \\
\hline & Dichlorvos & 17 & 1 & 0.154 \\
\hline & Fenpropathrin & 17 & 1 & 0.01 \\
\hline & Fludioxonil & 17 & 1 & 0.01 \\
\hline & Hexythiazox & 17 & 1 & 0.033 \\
\hline & Thiabendazole & 17 & 1 & 0.024 \\
\hline & 10 & 204 & 12 & \\
\hline \multirow{12}{*}{ Colombia } & Azoxystrobin & 262 & 50 & $0.02-0.6$ \\
\hline & Boscalid & 18 & 1 & 0.01 \\
\hline & Buprofezin & 18 & 1 & 0.01 \\
\hline & Chlorpyrifos & 15 & 2 & $0.02-0.03$ \\
\hline & Dimethomorph & 1 & 1 & 0.03 \\
\hline & Fenpropimorph & 17 & 1 & $0.005-1.005$ \\
\hline & Imazalil & 609 & 51 & $0.03-1.27$ \\
\hline & Myclobutanil & 184 & 33 & $0.01-0.4$ \\
\hline & Thiabendazole & 615 & 40 & $0.03-0.4$ \\
\hline & Tridemorph & 1 & 1 & 0.013 \\
\hline & Trifloxystrobin & 1 & 1 & 0.071 \\
\hline & 11 & 1741 & 182 & \\
\hline
\end{tabular}

Table 4 Continued

\begin{tabular}{|c|c|c|c|c|}
\hline $\begin{array}{l}\text { Origin of } \\
\text { Bananas }\end{array}$ & $\begin{array}{l}\text { Detected } \\
\text { esticides }\end{array}$ & $\begin{array}{c}\text { No. of } \\
\text { Samples } \\
\text { Analyzed }\end{array}$ & $\begin{array}{c}\text { No. of } \\
\text { Samples } \\
\text { Detected }\end{array}$ & $\begin{array}{c}\text { Residue } \\
\text { Concentration } \\
(\mathrm{mg} / \mathrm{kg})\end{array}$ \\
\hline \multirow{15}{*}{ Costa Rica } & Azoxystrobin & 663 & 78 & $0.01-0.6$ \\
\hline & Bifenthrin & 561 & 55 & $0.01-0.05$ \\
\hline & Boscalid & 18 & 1 & 0.03 \\
\hline & Buprofezin & 583 & 49 & $0.01-0.97$ \\
\hline & Chlorpyrifos & 157 & 17 & $0.01-0.1$ \\
\hline & Dithiocarbamates & 13 & 1 & 0.05 \\
\hline & Ethoprophos & 50 & 1 & 0.014 \\
\hline & Fenpropimorph & 351 & 41 & $0.01-0.7$ \\
\hline & Imazalil & 785 & 53 & $0.04-1.3$ \\
\hline & Myclobutanil & 182 & 19 & $0.02-0.3$ \\
\hline & Oxamyl & 2 & 2 & $0.022-0.028$ \\
\hline & Pyrimethanil & 8 & 8 & $0.01-0.03$ \\
\hline & Pyriproxyfen & 13 & 1 & 0.02 \\
\hline & Thiabendazole & 1179 & 102 & $0.01-1.1$ \\
\hline & 14 & 4565 & 428 & \\
\hline \multirow{10}{*}{ Cote D'lvoire } & Azoxystrobin & 212 & 15 & $0.03-1.5$ \\
\hline & Bifenthrin & 33 & 2 & $0.01-0.02$ \\
\hline & Bitertanol & 3 & 3 & $0.07-1$ \\
\hline & Boscalid & 73 & 4 & $0.01-0.5$ \\
\hline & DDAC & 1 & 1 & 0.01 \\
\hline & Dithiocarbamates & 17 & 1 & 0.06 \\
\hline & Fenpropimorph & 34 & 3 & $0.01-0.03$ \\
\hline & Imazalil & 1397 & 519 & $0.1-2.3$ \\
\hline & Myclobutanil & 16 & 1 & 0.2 \\
\hline & 9 & 1786 & 549 & \\
\hline \multirow{7}{*}{$\begin{array}{l}\text { Dominican } \\
\text { Republic }\end{array}$} & Azoxystrobin & 10 & 10 & $0.02-0.4$ \\
\hline & Chlorpyrifos & 10 & 2 & 0.01 \\
\hline & DDAC & 7 & 7 & $0.073-0.292$ \\
\hline & Imazalil & 49 & 3 & $0.07-0.3$ \\
\hline & Imidacloprid & 22 & 2 & $0.01-0.04$ \\
\hline & Spinosad & 35 & 2 & $0.01-0.02$ \\
\hline & 6 & 133 & 26 & \\
\hline \multirow{13}{*}{ Ecuador } & Bifenthrin & 75 & 5 & $0.008-0.01$ \\
\hline & Biphenyl & 35 & 1 & 0.01 \\
\hline & Carbaryl & 1 & 1 & 0.02 \\
\hline & Carbendazim & 35 & 1 & 0.01 \\
\hline & Chlorpyrifos & 105 & 9 & $0.01-0.03$ \\
\hline & DDAC & 1 & 1 & 0.011 \\
\hline & Diphenylamine & 24 & 1 & 0.01 \\
\hline & Fenpropimorph & 51 & 2 & $0.01-0.04$ \\
\hline & Fosetyl-aluminium & 1 & 1 & 5 \\
\hline & Imazalil & 1768 & 619 & $0.011-2.4$ \\
\hline & Thiabendazole & 593 & 32 & $0.01-0.823$ \\
\hline & Tridemorph & 1 & 1 & 0.017 \\
\hline & 12 & 2690 & 674 & \\
\hline
\end{tabular}


Table 4 Continued

\begin{tabular}{|c|c|c|c|c|}
\hline $\begin{array}{l}\text { Origin of } \\
\text { Bananas }\end{array}$ & $\begin{array}{l}\text { Detected } \\
\text { esticides }\end{array}$ & $\begin{array}{c}\text { No. of } \\
\text { Samples } \\
\text { Analyzed }\end{array}$ & $\begin{array}{c}\text { No. of } \\
\text { Samples } \\
\text { Detected }\end{array}$ & $\begin{array}{c}\text { Residue } \\
\text { Concentration } \\
(\mathrm{mg} / \mathrm{kg})\end{array}$ \\
\hline \multirow{7}{*}{$\begin{array}{c}\text { France } \\
\text { (Guadelpupe) }\end{array}$} & Azoxystrobin & 1 & 1 & 2.04 \\
\hline & Boscalid & 17 & 1 & 0.01 \\
\hline & Captan & 17 & 1 & 0.019 \\
\hline & Fludioxonil & 1201 & 2 & 0.011 \\
\hline & Imazalil & 17 & 1 & 0.041 \\
\hline & Iprodione & 17 & 1 & 0.01 \\
\hline & 6 & 1270 & 7 & \\
\hline \multirow{5}{*}{ Ghana } & Azoxystrobin & 207 & 13 & $0.02-0.8$ \\
\hline & Boscalid & 143 & 7 & $0.07-0.2$ \\
\hline & Imazalil & 63 & 4 & $0.07-1$ \\
\hline & Permethrin & 18 & 1 & 0.01 \\
\hline & 4 & 431 & 25 & \\
\hline \multirow{6}{*}{ Guatemala } & Azoxystrobin & 166 & 5 & $0.063-0.262$ \\
\hline & Carbendazim & 70 & 2 & $0.011-0.111$ \\
\hline & Chlorpyrifos & 532 & 17 & $0.016-0.256$ \\
\hline & Imazalil & 382 & 12 & $0.029-0.7$ \\
\hline & Thiabendazole & 90 & 3 & $0.04-0.262$ \\
\hline & 5 & 1240 & 39 & \\
\hline \multirow{5}{*}{ Honduras } & Azoxystrobin & 50 & 1 & 0.026 \\
\hline & Chlorpyrifos & 50 & 1 & 0.01 \\
\hline & Imazalil & 24 & 1 & 0.461 \\
\hline & Thiabendazole & 24 & 1 & 0.558 \\
\hline & 4 & 148 & 4 & \\
\hline \multirow[t]{2}{*}{ India } & Carbendazim & 32 & 1 & 0.005 \\
\hline & 1 & 32 & 1 & \\
\hline \multirow{3}{*}{ Japan } & Chlorfenapyr & 1 & 1 & 0.04 \\
\hline & Chlorpyrifos & 10 & 4 & $0.004-0.057$ \\
\hline & 2 & 11 & 5 & \\
\hline \multirow{9}{*}{ Mexico } & Bifenthrin & 61 & 2 & $0.026-0.049$ \\
\hline & Boscalid & 18 & 1 & 0.05 \\
\hline & Carbendazim & 50 & 1 & 0.27 \\
\hline & Chlorpyrifos & 88 & 4 & $0.01-0.016$ \\
\hline & Cyhalothrin & 17 & 1 & 0.01 \\
\hline & Fenpropidin & 36 & 2 & $0.02-0.07$ \\
\hline & Imazalil & 141 & 6 & $0.029-0.38$ \\
\hline & Thiabendazole & 362 & 11 & $0.038-1.1$ \\
\hline & 8 & 773 & 28 & \\
\hline \multirow{7}{*}{ Panama } & Azoxystrobin & 38 & 2 & $0.04-0.1$ \\
\hline & Bifenthrin & 18 & 1 & 0.03 \\
\hline & Buprofezin & 38 & 2 & $0.02-0.09$ \\
\hline & Imazalil & 59 & 2 & $0.474-0.605$ \\
\hline & Monocrotophos & 1100 & 1 & 0.03 \\
\hline & Thiabendazole & 62 & 3 & $0.05-0.305$ \\
\hline & 6 & 1315 & 11 & \\
\hline \multirow[t]{2}{*}{ Peru } & Fipronil & 2 & 2 & $0.02-0.07$ \\
\hline & 1 & 2 & 2 & \\
\hline
\end{tabular}

Table 4 Continued

\begin{tabular}{|c|c|c|c|c|}
\hline $\begin{array}{l}\text { Origin of } \\
\text { Bananas }\end{array}$ & $\begin{array}{l}\text { Detected } \\
\text { esticides }\end{array}$ & $\begin{array}{c}\text { No. of } \\
\text { Samples } \\
\text { Analyzed }\end{array}$ & $\begin{array}{c}\text { No. of } \\
\text { Samples } \\
\text { Detected }\end{array}$ & $\begin{array}{c}\text { Residue } \\
\text { Concentration } \\
(\mathrm{mg} / \mathrm{kg})\end{array}$ \\
\hline \multirow{6}{*}{ Philippines } & Cypermethrin & 1 & 1 & 0.05 \\
\hline & Fenuron & 50 & 1 & 0.01 \\
\hline & Fipronil & 12 & 12 & $0.006-0.015$ \\
\hline & Imidacloprid & 1 & 1 & 0.05 \\
\hline & Phosmet & 11 & 1 & 0.01 \\
\hline & 5 & 75 & 16 & \\
\hline \multirow{7}{*}{ Portugal } & Acrinathrin & 1112 & 38 & $0.029-3.3$ \\
\hline & Dimethoate & 1 & 1 & 0.05 \\
\hline & Endosulfan & 1201 & 1 & 0.19 \\
\hline & Methomyl & 1 & 1 & 0.077 \\
\hline & Spinosad & 1109 & 2 & $0.01-0.028$ \\
\hline & Thiabendazole & 1 & 1 & 0.0959 \\
\hline & 6 & 3425 & 44 & \\
\hline \multirow{4}{*}{ Spain } & Buprofezin & 1109 & 2 & $0.014-0.91$ \\
\hline & Chlorpyrifos-methyl & 1201 & 5 & 0.08 \\
\hline & Imidacloprid & 1109 & 2 & $0.012-0.06$ \\
\hline & 3 & 3419 & 9 & \\
\hline \multirow{3}{*}{ St Lucia } & Chlorpyrifos & 1 & 1 & 0.05 \\
\hline & Imazalil & 44 & 3 & $0.5-1.5$ \\
\hline & 2 & 45 & 4 & \\
\hline \multirow[t]{2}{*}{ Suriname } & Iprodione & 1 & 1 & 0.032 \\
\hline & 1 & 1 & 1 & \\
\hline \multirow{5}{*}{ United States } & Bifenthrin & 50 & 1 & 0.01 \\
\hline & Buprofezin & 150 & 3 & $0.005-0.025$ \\
\hline & Chlorpyrifos & 35 & 1 & 0.086 \\
\hline & Fenpropimorph & 150 & 3 & 0.011 \\
\hline & 4 & 385 & 8 & \\
\hline \multirow{4}{*}{$\begin{array}{l}\text { Windward } \\
\text { lslands }\end{array}$} & Chlorpyrifos & 18 & 1 & 0.04 \\
\hline & Fenpropimorph & 18 & 1 & 0.01 \\
\hline & Imazalil & 85 & 5 & $0.8-1.4$ \\
\hline & 3 & 121 & 7 & \\
\hline
\end{tabular}

2016년부터 우리나라에 바나나의 수입이 증가하고 있는 페루 및 필리핀에서 검출된 농약은 cypermethrin, fenuron, fipronil, imidacloprid 및 phosmet였다. 이 중 cypermethrin 및 imidacloprid 는 국내 기준에 각각 기준 이하 및 초과의 잔류량을 보였으며 다른 농약은 기준이 현재 없는 실정이다.

Cypermethrin은 나트륨 채널에 간섭하여 신경계에 작용하는 피레스로이드계 살충제이며 $\mathrm{K}_{\mathrm{ow}}$ 6.6으로 접촉 및 식독에 의해 작용한다[45].

Fenuron은 광합성 저해기작을 가진 제초제이고, fipronil은 신 경전달물질(gamma-aminobutyric acid, GABA) 수용체의 알로스 테릭 부위에 결합하여 염소 채널 차단으로 곤충의 신경과 근육 이 과잉 자극을 받도록 하는 기작을 가진 phenylpyrazole계 살 충제이다[46].

Imidacloprid는 neonicotinoid계 침투성 살충제로 토양에서부 
Table 5 List of the country of origin of bananas with 8 pesticides detected among global residual pesticide monitoring results from 2007 to 2018

\begin{tabular}{cl}
\hline \hline Detected Pesticides $^{\text {a) }}$ & \multicolumn{1}{c}{ Origin of Bananas (No. of Country) } \\
\hline Azoxystrobin & Belize, Cameroon, Colombia, Costa Rica, Cote D'lvoire, Dominican Republic, France, Ghana, Guatemala, \\
Bifenthrin & Brazil, Canada, Costa Rica, Cote D'lvoire, Ecuador, Mexico, Panama, United States (8) \\
Chlorpyrifos & Belize, Cameroon, Colombia, Costa Rica, Dominican Republic, Ecuador, Guatemala, Honduras, Japan, Mexico, St \\
Etofenprox & \\
Iprodione & France, Suriname (2) \\
Myclobutanil & Belize, Colombia, Costa Rica, Cote D'lvoire (4) \\
Prochloraz & \\
Thiamethoxam &
\end{tabular}

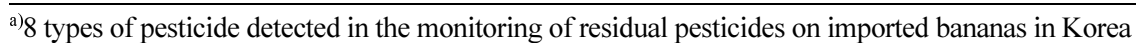

터 작물의 모든 조직으로 이동이 용이하고 접촉 및 식독을 통 하여 곤충의 체내로 들어가며 광범위하게 사용되고 있다[47]. 그 작용기작은 곤충의 니코틴성 아세틸콜린 수용체와 결합함으 로써 신경 자극 전달을 차단하여 곤충의 마비 및 사망을 초래 한다.

Phosmet는 아세틸콜린의 에스테르 부분에 결합하는 효소의 활성 부위를 차단하여 아세틸콜린 분해효소를 억제함으로써 아 세틸콜린의 가수분해를 방해하는 기작을 가진다.

우리나라의 잔류농약 모니터링에서 검출된 농약은 azoxystrobin, bifenthrin, chlorpyrifos, etofenprox, iprodione, myclobutanil, prochloraz 및 thiamethoxam이었으나, 이 농약이 검출된 바나나 의 원산지 표시가 없으므로 다른 나라의 모니터링 결과 중 이 8 종 농약이 검출된 바나나의 원산지를 Table 5에 나타내었다 [48]. USA, UK, EU 및 일본 모니터링에 의하면 azoxystrobin 은 벨리즈, 카메룬, 콜롬비아, 코스타리카, 코트디부아르, 도미니 카 공화국, 프랑스, 가나, 과테말라, 온두라스 및 파나마산에서 검출되었는데 프랑스산은 최고 잔류량이 $2.04 \mathrm{mg} / \mathrm{kg}$ 으로 우리 나라 및 Codex MRL을 초과한 수준이었다[21,27,28]. Chlorpyrifos 는 벨리즈, 카메룬, 콜롬비아, 코스타리카, 도미니카공화국, 에콰 도르, 과테말라, 온두라스, 일본, 멕시코, 세인트루시아, 미국 및 윈드워드제도산 바나나에서 검출되었다. Bifenthrin은 브라질, 캐 나다, 코스타리카, 코트디부아르, 에콰도르, 멕시코, 파나마 및 미국산 바나나에서 검출되었다. Iprodione은 우리나라에서 최고 잔류량 $2.383 \mathrm{mg} / \mathrm{kg}$ 으로 검출되었으며, 당시 기준은 $5.0 \mathrm{mg} / \mathrm{kg}$ 이어서 적합하였으나 현재기준은 $0.02 \mathrm{mg} / \mathrm{kg}$ 으로 우리나라 MRL 을 초과하는 수준이다[26,27]. 미국 및 $\mathrm{EU}$ 모니터링에서 iprodione은 각각 프랑스 및 수리남산에서 검출되었는데 프랑스 산은 혼합 과일 퓌레 제품이었다[18,22]. Iprodione은 삼투압 신 호전달에서 미토겐 활성화 단백질(mitogen activated protein, $\mathrm{MAP}$ ) 히스티딘 효소를 저해하여 곰팡이 포자의 발아 및 균사 체의 성장을 억제하는 접촉 살균제이다[38]. Myclobutanil은 벨 리즈, 콜롬비아, 코스타리카 및 코트디부아르산에서 검출되었다. Etofenprox, prochloraz 및 thiamethoxam은 일본, 우리나라 및 $\mathrm{EU}$ 모니터링에서 검출되었으나, 원산지가 표시되어 있지 않았 다. 다른 나라의 모니터링에서 azoxystrobin 및 bifenthrin은 다 수의 원산지 중 코스타리카산 바나나에서 각각 78 및 55건으로 가장 높은 검출 건수를 보였고, azoxystrobin의 검출빈도로는 콜
롬비아산에서 $19 \%$ 로 가장 높았다. 벨리즈산 바나나 중 chlorpyrifos는 $22.7 \%$ 의 높은 검출빈도 결과를 보였고, 콜롬비아 산 바나나 중 chlorpyrifos 및 myclobutanil은 각각 13.3 및 $17.9 \%$ 의 검출빈도를 보였다. 코스타리카산 바나나 중 chlorpyrifos와 myclobutanil의 농약 검출빈도는 10.8 및 $10.4 \%$ 였다.

감사의 글 본 연구는 2018년도 식품의약품안전처의 연구개발비 (17162MFDS029)로 수행되었으며 이에 감사드립니다.

\section{초 록}

이 연구는 농산물의 원산지에 따른 검출 농약을 조사하여 대한 민국의 수입 바나나 중 잔류농약 안전 관리 자료로 활용하고자 하였다. 미국, 일본, EU, 영국 및 대한민국의 2007에서 2018년 까지 바나나 중 잔류농약 검사 결과를 활용하여 검출 농약, 검 사 건수, 농약 검출 건수 및 검출량으로 정리하였다. 이들 바나 나의 잔류농약 검사에서 검출된 농약은 총 109 종이었으며, 전 체 검사 건수는 206,894 건이었다. 이 중 9,483 건에서 잔류농약 이 검출되었으며, 농약 검출률은 $4.58 \%$ 였다. 검출된 농약은 chlorpyrifos, imazalil, methyl-bromide, azoxystrobin, carbendazim, pretilachlor 및 thiabendazole 등 이었으며, 이 농약들의 검출률 은 $10.62-24.62 \%$ 범위였다. Chlorpyrifos가 검출 건수에서 가장 많이 검출되었으며, 다음으로 imazalil, azoxystrobin, thiabendazole, bifenthrin 및 carbendazim 순이었다. EU, 일본, 미국, 영국 및 대한민국의 잔류농약 검사에서 각각 $85,57,23,18$ 및 8 종 농 약이 검출되었다. Azoxystrobin, bifenthrin 및 chlorpyrifos는 모 든 국가의 모니터링에서 검출되었다. 코스타리카 및 에콰도르산 바나나에서 각각 14 및 12 종 농약이 검출되었다. Imazalil 및 thiabendazole은 각각 16 및 11 개 원산지에서 검출되었다. Myclobutanil 및 iprodione은 각각 4 및 2개국산에서 검출되었 다. Azoxystrobin 및 bifenthrin은 코스타리카산 바나나에서 각 각 11.8 및 $9.8 \%$ 검출 건수를 보였고, azoxystrobin의 검출률은 콜롬비아산에서 $19 \%$ 였다. 벨리즈산, 콜롬비아산 및 코스타리카 산 바나나 중 chlorpyrifos는 각각 $22.7,13.3$ 및 $10.8 \%$ 의 검출 률을 보였고, 콜롬비아산 및 코스타리카산 바나나 중 myclobutanil의 검출률은 각각 17.9 및 $10.4 \%$ 였다. 
Keywords Banana $\cdot$ Imported food $\cdot$ Monitoring $\cdot$ Pesticide residues

\section{References}

1. Dan K, Kim SJ (2010) BANANA: The Fate of the Fruit That Changed the World, IMAGO, Seoul

2. aT Korea Agro Fisheries \& Food Trade Corporation (2017) 2016 Distribution Status of Major Agricultural Products, Naju, p 919

3. FAOSTAT (2017) banana http://www.fao.org/faostat/en/\#data/QC/visualize, Accepted 26 April 2019

4. Korea Customs Service, Trade statistics (2019) https://unipass.customs. go.kr/ets/index.do, Accepted 26 April 2019

5. Ji YJ (2017) Monitoring and Risk Assessment of Pesticide Residues for Agricultural Commodities in Korean and Foreign country. Daegu University, p 10, 73

6. Korea Rural Economic Institute (2015) Trend of Agricultural Trade with FTA Partners 3(4)

7. MFDS (2015a) Yearbook of Imported Food Inspection 17, p 134, Ministry of Food and Drug Safety, Cheongju, Korea

8. MFDS (2016) Yearbook of Imported Food Inspection 18, p 152, 288, 289, Ministry of Food and Drug Safety, Cheongju, Korea

9. MFDS (2017) Yearbook of Imported Food Inspection 19, p 106, 308, 309, Ministry of Food and Drug Safety, Cheongju, Korea

10. MFDS (2018) Yearbook of Imported Food Inspection 20, p 156, 157, Ministry of Food and Drug Safety, Cheongju, Korea

11. Noh HH, Park YS, Kang KW, Park HK, Lee KH, Lee JY, Yeop KW, Choi SR, Kyung KS (2010) Monitoring of Pesticide Residues in Leafy Vegetables Collected from Wholesale and Traditional Markets in Cheongju. Korean J Pest Sci 14(4): 381-393

12. Lee JH, Park HW, Keum YS, Kim JH (2008) Post-harvest Safety: Residue Patterns of Boscalid on Cucumber during Storage or by Washing. Kor J Hort Sci Technol AHC 2008: 141

13. Kim SH (2013) Residual Characteristics and Processing Factors of Difenoconazole and Pymetrozine in Water Celery. Chungbuk National University

14. Aquino A, Navickiene S (2009) MSPD Procedure for Determination of Carbofuran, Pyrimethanil and Tetraconazole Residues in Banana by GCMS, Chromatographia. doi: 10.1365/s10337-009-1324-4

15. Llorent-Martinez EJ, Garcia-Reyes JF, Ortega-Barrales P, Molina-Diaz A (2007): Multicommuted fluorescence based optosensor for the screening of bitertanol residues in banana samples, Food chemistry 102(3): 676682

16. Veneziano A, Vacca G, Arana S, Simone FD, Rastrelli L (2004) Determination of carbendazim, thiabendazole and thiophanate-methyl in banana (Musa acuminata) samples imported to Italy. Food chemistry 87(3): 383-386

17. Hernandez-Borges J, Cabrera JC, Rodriguez-Delgado MA, HernandezSuarez EM, Sauco VG (2009) Analysis of pesticide residues in bananas harvested in the Canary Islands (Spain). Food chemistry 113(1): 313319

18. U.S. FDA. Pesticide Residue Monitoring Program Fiscal Year 2010-2016 Pesticide Report. http:/www.fda.gov/Food/FoodborneIllnessContaminants/ Pesticides/ucm2006797.htm, Accepted 26 April 2019

19. MHLW a (Ministiry of Health, Labour and Welfare). Test Results such as Pesticide Residues in Food for 2007-2015. https://www.mhlw.go.jp/ stf/seisakunitsuite/bunya/kenkou iryou/shokuhin/zanryu/index.html, Accepted 26 April 2019

20. MHLW b (Ministiry of Health, Labour and Welfare). Imported Foods Inspection Services Home Page. http://www.mhlw.go.jp/english/topics/ importedfoods/index.html, Accepted 26 April 201937. Cho YS, Kang JB, Kim YH, Jeong JA, Huh JW, Lee SH, Lim YS, Bae HJ, Kang HG
Lee JH, Jung ES, Lee BH, Park YB, Lee JB (2012) A survey on pesticide residues of imported fruits circulated in Gyeonggido. Korean $\mathrm{J}$ Pest Sci 16(3): 195-201

21. European Food Safety Authority (2009-2015) The European Union report on pesticide residues in food

22. EU RASFF (the Rapid Alert System for Food and Feed) (2014, 2016, 2017) https://webgate.ec.europa.eu/rasff-window/portal/?event=Search Form\&cleanSearch=1\#, Accepted 26 April 2019

23. PRiF a (Pesticide Residues in Food). Pesticide Residues Monitoring Programme for 2012, 2015, 2018. https://webarchive.nationalarchives. gov.uk/20151023165203/http://www.pesticides.gov.uk/guidance/industries/ pesticides/advisory-groups/PRiF/, https:/www.gov.uk/government/ collections/pesticide-residues-in-food-results-of-monitoring-programme, Accepted 26 April 2019

24. PRiF b (Pesticide Residues in Food). School Fruit and Vegetable Scheme report on pesticide residues monitoring for 2015, 2016, 2017. https:// www.gov.uk/government/collections/pesticide-residues-in-food-resultsof-monitoring-programme, Accepted 26 April 2019

25. PRiF c (Pesticide Residues in Food). Industry data report for 2012, 2015. https://webarchive.nationalarchives.gov.uk/20151023165203/http://www. pesticides.gov.uk/guidance/industries/pesticides/advisory-groups/PRiF/, https://www.gov.uk/government/collections/pesticide-residues-in-foodresults-of-monitoring-programme, Accepted 26 April 2019

26. MFDS (2012, 2013, 2015, 2016) Monitoring of Pesticide Residues in Agricultural Products, Ministry of Food and Drug Safety, Cheongju, Korea

27. MFDS (2019) MRLs for Pesticides in Foods. Ministry of Food and Drug Safety, Cheongju, Korea

28. Codex Alimentarius (2019) Pesticides MRLs http://www.fao.org/faowho-codexalimentarius/codex-texts/dbs/pestres/pesticides/en/, Accepted 26 April 2019

29. Hwang J, Jeon SO, Lee SH, Lee SE, Hur JH, Kim KR, Kim JE (2014) Distribution Patterns of Organophosphorous Insecticide Chlorpyrifos Absorbed from Soil into Cucumber. Korean J Pest Sci 18(3): 148-155

30. Li R, Dong F, Xu J, Liu X, Wu X, Pan X, Tao Y, Chen Z, Zheng Y (2017) Enantioseparation of Imazalil and Monitoring of Its Enantioselective Degradation in Apples and Soils Using Ultrahigh-Performance Liquid Chromatography-Tandem Mass Spectrometry. J Agric Food chem 65(16): $3259-3267$

31. EFSA (2014) The 2012 European Union report on pesticide residues in food. European Food Safety Authority

32. EU Pesticide database (2019) https://ec.europa.eu/food/plant/pesticides/ eu-pesticides-database/public/?event=pesticide.residue.CurrentMRL\& language $=\mathrm{EN}$, Accepted 26 April 2019

33. MFDS (2015b) MRLs for Pesticides in Foods. Ministry of Food and Drug Safety, Cheongju, Korea

34. Ryu KS, Park PH, Kim KY, Lim BG, Kang MS, Lee YJ, Yoon MH (2018) Monitoring and Risk Assessment of Pesticide Residues in Agricultural Products for Raw Juice in Gyeonggi-Do, Korea. J Fd Hyg Safety 33(5): 339-346

35. Hwang LH, Cho TH, Cho IS, Eom JH, Choe BC, Park YH, Kim HJ, Kim JH (2010) Residue Levels of Pesticides in Post-Harvest Treated Import Fruits During Storage. J Fd Hyg Safety 25(3): 245-250

36. Chung SJ, Kim HY, Kim JH, Yeom MS, Cho JH, Lee SY (2014) Monitoring of Pesticide Residues and Risk Assessment in Some Fruits on the Market. in Incheon, Korea. Korean J Environ Agric 33(2): 111120

37. Cho YS, Kang JB, Kim YH, Jeong JA, Huh JW, Lee SH, Lim YS, Bae HJ, Kang HG, Lee JH, Jung ES, Lee BH, Park YB, Lee JB (2012) A survey on pesticide residues of imported fruits circulated in Gyeonggido. Korean J Pest Sci 16(3): 195-201

38. Turner JA (2015) The Pesticide Manual A World Compendium Seventeenth Edition. BCPC, Alton, Hampshire UK

39. Korean Crop Protection Association (2017) Guidance Document of Crop Protection Products(Pesticide), Seoul, Korea 
40. Lee JY, Noh HH, Park HK, Kim JC, Jeong HR, Jin MJ, Kyung KS (2015) Residual Characteristics and Behavior of Azoxystrobin in Ginseng by Cultivation Conditions. Korean J Pest Sci 19(1): 14-21

41. Choi GH, Lee DY, Ryu SH, Park BJ, Moon BC, Kim JH (2018) Investigation of the Bioconcentration Factor of Endosulfan for Rice from Soil. Korean J Pest Sci 22(1): 25-28

42. Choi GH, Jeong DK, Lim SJ, Ro JH, Ryu SH, Park BJ, Moon BC, Kim JH (2017) Plant uptake potential of endosulfan from soil by carrot and spinach. J Appl Biol Chem 60(4): 339-342

43. Weber J, Halsall CJ, Muir D, Teixeira C, Small J, Solomon K, Hermanson M, Hung H, Bidleman T (2010) Endosulfan, a global pesticide: A review of its fate in the environment and occurrence in the Arctic. Sci Total Environ 408: 2966-2984

44. Ahn JH, Park IC, Kim WG, Han BH, You JH (2017) Effect of an Organochlorine Insecticide, Endosulfan on Soil Bacteria Community as
Evaluated by $16 \mathrm{~S}$ rRNA Gene Analysis. Korean J Pest Sci 21(1): 1-8

45. Yoo J, Park CG, Lee SW, Choi BR (2001) Cross Resistance of Cypermethrin-and Methomyl-Resistance and Linkage Group Analysis on Cypermethrin Resistance in House Fly (Musca domestica L.). Korean J Appl Entomol 40(4): 337-344

46. Park SJ, Shin YN, Jeong MH, Paik MK, Lee JB, You AS, Hong SS, Ihm YB (2014) Study on Development Effect on Zebrafish Embryo by Alachlor, Butachlor and Fipronil. Korean J Pest Sci 18(1): 14-20

47. Seo EK, Kim TK, Hong SM, Kwon HY, Kwon JH, Son KA, Kim JE, Kim DH (2013) Analysis of Systemic Pesticide Imidacloprid and Its Metabolites in Pepper using QuEChERS and LC-MS/MS. Korean J Pest Sci 17(4): 264-270

48. MFDS (2014) Yearbook of Imported Food Inspection 16, p 242-243, Ministry of Food and Drug Safety, Cheongju, Korea 